\title{
JAARCIJFERS VAN SURINAME
}

\author{
DOOR
}

L. C. PREY

De op finantieel, economisch of sociaal gebied omtrent Suriname bestaande litteratuur is zeer schaars; betrouwbare gegevens treft men eigenlijk alleen aan in de officieele begrootingsstukken en in de Koloniale verslagen. Statistieken, in den geest van de in ons land bekende "Jaarcijfers", bestaan in dit, in menig opzicht zoo onontwikkelde, land niet. En juist hier zijn deze niet te ontberen, wanneer men zich een beeld wil vormen van de structuur van het gewest, zonder genoodzaakt te zijn daartoe een menigte heel of half officieele stukken te raadplegen.

Zulke statistieken zijn een belangrijk hulpmiddel bij de bestudeering onder meer van den economischen en socialen toestand. Zij geven een exact en zakelijk antwoord op de bij hen, die zich voor die vraagstukken interesseeren, van nature opkomende vraag: hoe het vroeger is geweest.

Bij de raadpleging dient men evenwel niet uit het oog te verliezen, dat statistieken niet anders zijn dan volgens een bepaalde methode gerangschikte cijfers of cijfergroepen en dat deze geen licht verschaffen aangaande de factoren, waarvan elk cijfer het product is, dat wil dus zeggen, dat men voorzichtig moet te werk gaan met het trekken van conclusies, in het bijzonder ten aanzien van de voor elk jaar afzonderlijk vermelde cijfers. Over een reeks van jaren beschouwd geven deze cijfers echter een beeld van opgang of teruggang, dat in den regel als een afspiegeling van den werkelijken toestand kan worden aanvaard.

Ik heb daartoe een dergelijke statistiek opgebouwd, aanvangende in het jaar 1920 en betrekking hebbende op klimaat, landbouw, handel, scheepvaart, bevolking en alle takken van bestuurszorg, die voor een beoordeeling van de ontwikkelingsmogelijkheden van belang zijn.

Niet voor ieder jaar kon over cijfers worden beschikt; ook 
moet men met ieder cijfer nog voorzichtiger zijn dan, gelijk hiervoor betoogd, bij raadpleging van iedere statistiek geboden is. Vooral in vroegere jaren nam men het met het verschaffen van cijfers niet zoo nauw; in latere jaren is meer contrôle op de juistheid der cijfers uitgeoefend. Over een reeks van jaren beschouwd zijn echter aan deze Jaarcijfers wel voldoend veilige ,aanwijzingen" te ontleenen.

Behalve met het verschaffen van een, zij het dan niet in alle opzichten volledig, statistisch beeld van het land, als voorloopig hulpmiddel, is het doel met dit werk althans een begin te maken. Eenmaal verschenen, zal wellicht het nut ervan worden ingezien en van Overheidswege het werk systematisch worden voortgezet, omdat betrouwbare Jaarcijfers ook voor het Bestuur van groote waarde zijn.

De cijfers gaan tot en met 1937. De bedoeling is elk jaar de aanvullende cijfers te geven, zoodra daarover kan worden beschikt. 
WEERKUNDIGE WAARNEMINGEN TE PARAMARIBO EN REGENVAL TE PARAMARIBO EN OP ENKELE ANDERE PLAATSEN.

\begin{tabular}{|c|c|c|c|c|c|c|c|c|c|c|c|c|c|c|}
\hline \multirow[t]{2}{*}{ Jaren } & \multicolumn{2}{|c|}{$\begin{array}{l}\text { Luchtdruk } \\
\text { in mm her- } \\
\text { leid op } 0^{\circ} \mathrm{C}\end{array}$} & \multicolumn{2}{|c|}{$\begin{array}{l}\text { Tempera- } \\
\text { tuur } \\
\text { graden C. }\end{array}$} & \multicolumn{2}{|c|}{$\begin{array}{l}\text { Damp- } \\
\text { drukking } \\
\text { in } \mathrm{mm}\end{array}$} & \multirow{2}{*}{$\begin{array}{l}\text { Betrek- } \\
\text { kelijke } \\
\text { vochtig- } \\
\text { heid in } \\
\% \text { gem. }\end{array}$} & \multirow{2}{*}{$\begin{array}{l}\text { Bewol- } \\
\text { king } \\
(0-10) \\
\text { gemidd. }\end{array}$} & \multicolumn{6}{|c|}{ Totale regenval in $\mathrm{mm}$} \\
\hline & $\max$ & $\min$. & $\max$. & $\min$. & $\max$. & $\min$. & & & $\begin{array}{l}\text { Para- } \\
\text { maribo }\end{array}$ & $\begin{array}{c}\text { Repu- } \\
\text { bliek }\end{array}$ & $\left|\begin{array}{c}\text { Browns } \\
\text { weg }\end{array}\right|$ & $\begin{array}{l}\text { Alli- } \\
\text { ance }\end{array}$ & $\begin{array}{c}\text { Coro- } \\
\text { nie }\end{array}$ & $\begin{array}{l}\text { Nicke- } \\
\text { rie }\end{array}$ \\
\hline 1920 & 763.1 & 759.2 & 33.7 & 19.1 & 25.4 & 17.2 & 82 & 5.4 & 2032.6 & 2000.0 & 2177.2 & 1908.7 & 1642.7 & 1130.4 \\
\hline 1921 & 764.4 & 755.9 & 33.6 & 18.7 & 24.6 & 16.9 & 85 & 5.8 & 2102.7 & 1895.5 & 2722.8 & 2221.8 & 1780.7 & 1673.7 \\
\hline 1922 & 764.4 & 755.7 & 34.1 & 20.5 & 25.6 & 16.9 & 82 & 6.4 & 2427.2 & 2033.7 & 2264.5 & 1784.8 & 2032.3 & 1936.1 \\
\hline 1923 & 763.8 & 756.5 & 34.7 & 18.1 & 25.0 & 12.8 & 82 & 6.9 & 2290.6 & 2185.2 & 2227.5 & 2012.4 & 1692.8 & 1421.4 \\
\hline 1924 & 763.6 & 757.1 & 34.2 & 17.0 & 24.9 & 15.5 & 81 & 7.1 & 2004.5 & 1409.9 & 1994.4 & 1817.6 & 1678.0 & 1631.0 \\
\hline 1925 & 763.3 & 756.8 & 34.9 & 17.2 & 25.0 & 13.9 & 80 & 7.1 & 1715.7 & 1623.9 & 1906.1 & 1500.1 & 1245.1 & 1115.9 \\
\hline 1926 & 764.0 & 756.3 & 34.6 & 17.3 & 25.5 & 13.2 & 79 & 7.4 & 1797.6 & 1639.1 & 1879.1 & 1500.1 & 1192.4 & 1322.1 \\
\hline 1927 & 764.2 & 754.5 & 34.5 & 17.2 & 25.6 & 16.2 & 82 & 7.3 & 2610.1 & 2518.9 & 2567.0 & 2431.0 & 2580.4 & 2624.2 \\
\hline 1928 & 763.8 & 756.1 & 35.0 & 20.0 & 25.7 & 14.4 & 81 & 7.0 & 2619.7 & 1991.2 & 2078.3 & 2154.8 & 1533.1 & 1901.0 \\
\hline 1929 & 763.8 & 755.6 & 35.2 & 18.1 & 25.2 & 15.4 & 80 & 7.3 & 2018.7 & 1752.9 & 1996.5 & 1632.7 & 1667.1 & 1813.7 \\
\hline 1930 & 764.9 & 756.6 & 35.6 & 20.0 & 25.3 & 14.6 & 81 & 7.1 & 2106.3 & 1517.6 & 2114.8 & 1779.8 & 1473.1 & 1748.0 \\
\hline 1931 & 764.9 & 756.1 & 35.0 & 20.3 & 25.2 & 16.3 & 80 & 6.9 & 2148.7 & 2025.5 & 2205.3 & 2095.1 & 1671.7 & 2190.3 \\
\hline 1932 & 764.3 & 757.2 & 36.0 & 18.9 & 25.0 & 13.3 & 80 & 6.4 & 2358.7 & 1848.7 & 2187.2 & 2203.6 & 1827.5 & 19046 \\
\hline 1933 & 7650 & 7569 & 34.7 & 18.2 & 25.4 & 15.1 & 81 & 6.6 & 2530.5 & 2511.5 & 2246.7 & 2529.2 & 2468.8 & 2399.5 \\
\hline 1934 & 764.3 & 757.0 & 34.4 & 19.1 & 25.1 & 14.4 & 80 & 6.6 & 1729.2 & 1906.4 & 2154.5 & 1454.3 & 1172.9 & 1167.8 \\
\hline 1935 & 764.5 & 757.6 & 35.3 & 17.9 & 24.9 & 15.4 & 79 & 5.5 & 1707.8 & 1759.3 & 2094.8 & 1880.0 & 1514.2 & 1892.9 \\
\hline 1936 & 764.6 & 755.4 & 35.7 & 18.1 & 25.9 & 14.7 & 80 & 5.5 & 2453.0 & 2142.5 & 2486.7 & 1976.0 & 1588.3 & 1761.3 \\
\hline 1937 & $\mid 764.8$ & 756.7 & 35.9 & 18.3 & 25.3 & 14.7 & 78 & 5.7 & 2012.6 & 2279.3 & 2083.5 & 2148.0 & 1638.2 & 2309.9 \\
\hline
\end{tabular}


GEMIDDELDE REGENVAL BOVEN VERSCHILLENDE STROOMGEBIEDEN

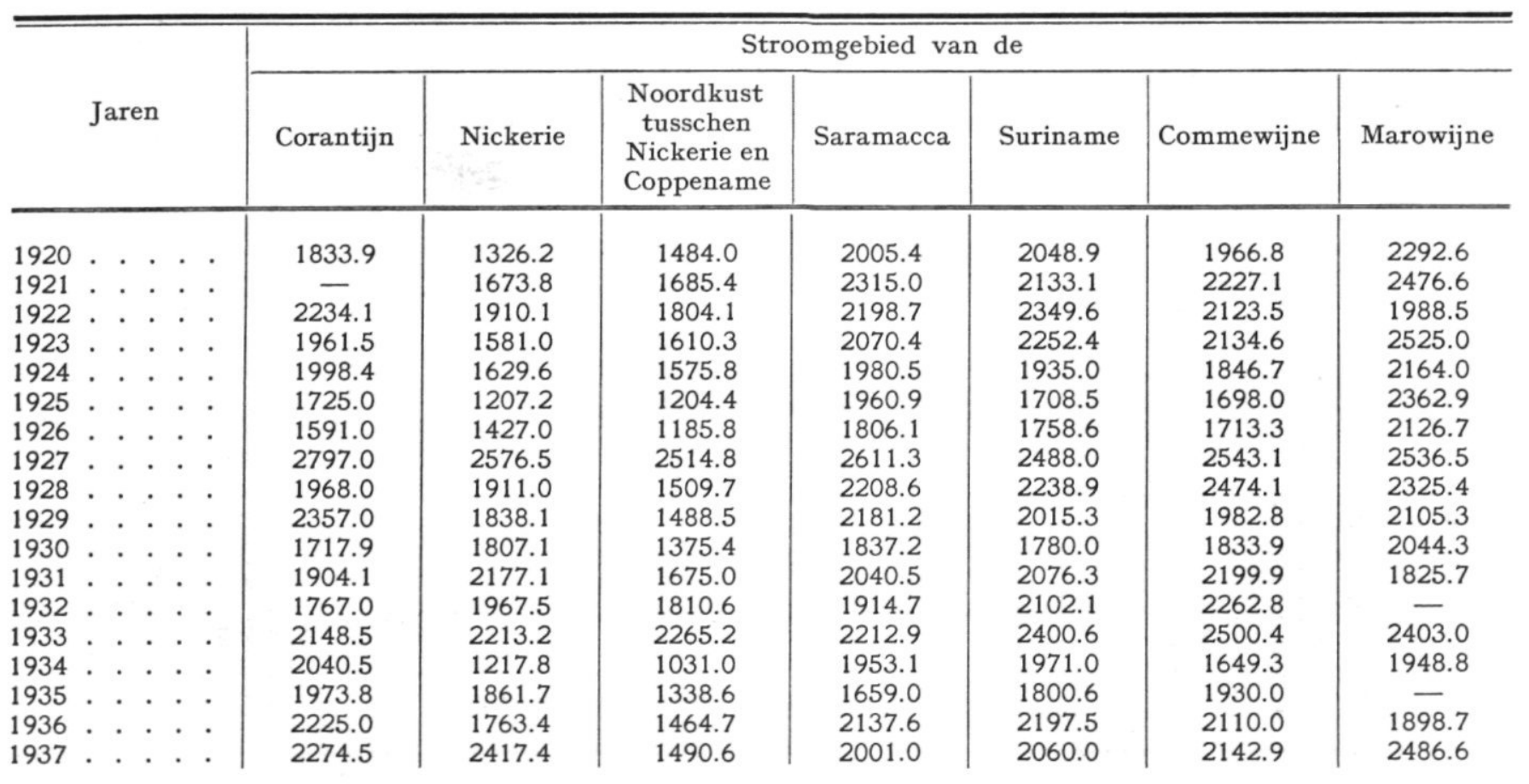

岁 
ALGEMEEN OVERZICHT VAN DEN LOOP DER BEVOLKING (ZONDER BOSCHNEGERS EN INDIANEN).

\begin{tabular}{|c|c|c|c|c|c|c|c|c|c|c|c|c|c|c|c|c|}
\hline \multirow{3}{*}{ Jaren } & \multirow{3}{*}{$\begin{array}{l}\text { Totale } \\
\text { bevol- } \\
\text { king } \\
\text { op 31 } \\
\text { Dec. }\end{array}$} & \multirow{3}{*}{ 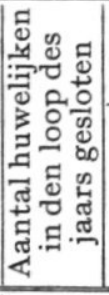 } & \multicolumn{7}{|c|}{ Levend aangegeven } & \multicolumn{3}{|c|}{$\begin{array}{l}\text { Levenloos } \\
\text { aangegeven }\end{array}$} & \multirow{3}{*}{ 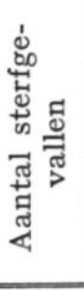 } & \multirow{3}{*}{ 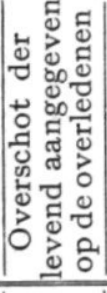 } & \multirow{3}{*}{ 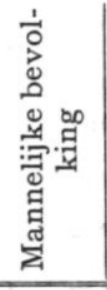 } & \multirow{3}{*}{ 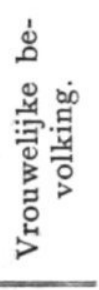 } \\
\hline & & & \multicolumn{3}{|c|}{ wettig } & \multicolumn{3}{|c|}{ onwettig } & \multirow{2}{*}{ 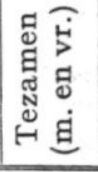 } & \multirow{2}{*}{ 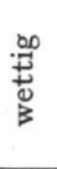 } & \multirow{2}{*}{ 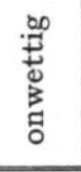 } & \multirow{2}{*}{ 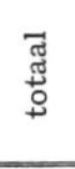 } & & & & \\
\hline & & & $\mathrm{m}$. & vr. & totaal & $\mathrm{m}$. & vr. & totaal & & & & & & & & \\
\hline 1920 & 107.354 & 543 & 444 & 441 & 885 & 1163 & 1176 & 2339 & 3224 & 38 & 178 & 216 & 2080 & 1144 & - & \\
\hline 192 & 107. & 427 & 49 & 53 & 102 & 120 & 133 & & & 41 & & & & 69 & 56.778 & 50.9 \\
\hline 1922 & 110 & 484 & 438 & 431 & & 129 & 120 & & 3 & & 20 & & 2189 & 1180 & 01 & \\
\hline 192 & 112 & 395 & 469 & 426 & & & 122 & & 3 & 4 & & & & 50 & & \\
\hline 1924 & 116 & 403 & 52 & 48 & 101 & & 14 & & & & & & & & & \\
\hline 1925 & 119 & 395 & $47 ?$ & 47 & & & & & & & & & & & 31 & \\
\hline 1926 & 122.982 & 365 & 481 & 47 & 95 & 1494 & & & & & & & 2223 & 1699 & 40 & \\
\hline 1927 & 26.041 & 440 & 403 & 402 & 80 & 1363 & 131 & 2676 & & & & 21 & 2107 & 1374 & 88 & \\
\hline 1928 & 29.2 & 467 & 459 & 426 & 88 & 1495 & 1445 & 2940 & & 2 & 18. & 210 & 1925 & 1900 & 93 & \\
\hline 192 & 16 & 459 & 466 & 472 & 938 & 1685 & 1708 & 3393 & & 4 & 20 & 25 & 2032 & 2299 & 11 & 63 \\
\hline 1930 & 13 & 480 & 473 & 425 & 898 & 1677 & 1584 & 3261 & & 1 & 17 & 19 & 1855 & 2304 & 96 & 64 \\
\hline 1931 & 136.2 & 386 & 446 & 471 & 917 & 1623 & 162 & 3249 & & 3 & 20 & 242 & 1966 & 2200 & 34 & 65.9 \\
\hline 1932 & 138.6 & 420 & 486 & 462 & 948 & 1620 & 161 & 3238 & & 4 & 18 & 22 & 1827 & 2359 & 17 & 67.27 \\
\hline 193. & 141.5 & 438 & 483 & 482 & 965 & 1830 & 1737 & 3567 & & 4 & 17 & $21 c$ & 1853 & 2679 & & \\
\hline & & 367 & 496 & 465 & 961 & 1799 & 1714 & 3513 & 4474 & 53 & 171 & 224 & 1835 & 2639 & 74.246 & \\
\hline 1935 & 146.843 & 442 & 550 & 479 & 1029 & 1859 & 1918 & 3777 & 4806 & 42 & 231 & 273 & 1734 & 3072 & 75.356 & \\
\hline 1936 & 148.971 & 386 & 494 & 526 & 1020 & 1768 & 1748 & & 4536 & 33 & 190 & 223 & 1916 & 2620 & 76.298 & 72.67 \\
\hline 1937 & 150.896 & 395 & 474 & 492 & 966 & 1768 & 1790 & 3558 & 4524 & 47 & 150 & 197 & 1854 & 2670 & 77.009 & 73.88 \\
\hline
\end{tabular}


BEVOLKING IN DE DISTRICTEN EN IN HET GEWEST

\begin{tabular}{|c|c|c|c|c|c|c|c|c|c|c|c|c|c|c|c|c|}
\hline \multirow{3}{*}{ 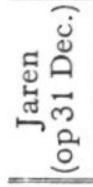 } & \multirow{3}{*}{ 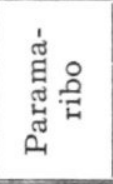 } & \multirow{2}{*}{\multicolumn{2}{|c|}{$\begin{array}{c}\text { District } \\
\text { Suriname }\left({ }^{1}\right)\end{array}$}} & \multirow{2}{*}{\multicolumn{2}{|c|}{$\begin{array}{c}\text { DistrictCom- } \\
\text { mewijne(1) }\end{array}$}} & \multirow{2}{*}{\multicolumn{2}{|c|}{$\mid \begin{array}{c}\text { District } \\
\text { Marowijne (1) }\end{array}$}} & \multirow{3}{*}{ 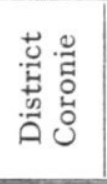 } & \multirow{3}{*}{ 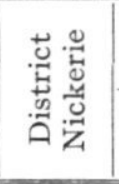 } & \multirow{2}{*}{\multicolumn{2}{|c|}{$\begin{array}{l}\text { District Sa- } \\
\text { ramacca }(1)\end{array}$}} & \multirow{2}{*}{\multicolumn{2}{|c|}{$\begin{array}{l}\text { District } \\
\text { Para }\left({ }^{2}\right)\end{array}$}} & \multirow{3}{*}{ 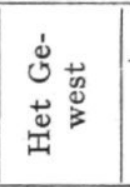 } & \multicolumn{2}{|c|}{ Bovendien } \\
\hline & & & & & & & & & & & & & & & \multirow{2}{*}{ 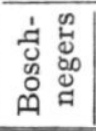 } & \multirow{2}{*}{ 㿝 总 } \\
\hline & & $\begin{array}{c}\text { Bene- } \\
\text { den }\end{array}$ & $\begin{array}{l}\text { Bo- } \\
\text { ven }\end{array}$ & $\begin{array}{c}\text { Bene- } \\
\text { den }\end{array}$ & $\begin{array}{l}\text { Bo- } \\
\text { ven }\end{array}$ & $\left|\begin{array}{c}\text { Maro- } \\
\text { wijne }\end{array}\right|$ & $\begin{array}{c}\text { Cotti- } \\
\text { ca }\end{array}$ & & & $\begin{array}{c}\text { Bene- } \\
\text { den }\end{array}$ & $\begin{array}{l}\text { Bo- } \\
\text { ven }\end{array}$ & $\begin{array}{c}\text { Bene- } \\
\text { den }\end{array}$ & $\begin{array}{l}\text { Bo- } \\
\text { ven }\end{array}$ & & & \\
\hline 1920 & - & - & - & - & - & - & - & - & - & - & - & - & - & - & \multirow{18}{*}{$\begin{array}{l}8 \\
\stackrel{8}{+} \\
+1\end{array}$} & \multirow{18}{*}{$\begin{array}{l}\text { 을 } \\
\text { H } \\
\text { H }\end{array}$} \\
\hline 1921 & - & - & - & - & - & - & - & - & - & - & - & - & - & - & & \\
\hline 1922 & 43.757 & 9.885 & 3.449 & 13.615 & 1.204 & 9.719 & 15.699 & 2.641 & 10.157 & 5.688 & 191 & 11.124 & 42.552 & 110.933 & & \\
\hline 1923 & 44.772 & 10.308 & 3.349 & 13.667 & 1.177 & 9.219 & 15.858 & 2.647 & 10.548 & 5.642 & 185 & 11.273 & 32.480 & 112.827 & & \\
\hline 1924 & 45.523 & 11.115 & 3.463 & 14.212 & 1.662 & 920 & 6.026 & 2.683 & 11.007 & 5.651 & 176 & 11.575 & 5.545 & 116.058 & & \\
\hline 1925 & 45.554 & 11.763 & 3.454 & 15.273 & 1.208 & 930 & 6.666 & 2.748 & 11.794 & 5.650 & 142 & 12.343 & 32.401 & 119.926 & & \\
\hline 1926 & 45.703 & 12.227 & 3.066 & 16.793 & 1.081 & 918 & 7.432 & 2.674 & 12.645 & 5.315 & 142 & 12.770 & 2.216 & 122.982 & & \\
\hline 1927 & 45.791 & \multicolumn{2}{|c|}{30.605} & \multicolumn{2}{|c|}{23.779} & \multicolumn{2}{|c|}{2.714} & 2.805 & 13.843 & \multicolumn{2}{|c|}{6.504} & \multicolumn{2}{|c|}{-} & 126.041 & & \\
\hline 1928 & 46.929 & \multirow{2}{*}{\multicolumn{2}{|c|}{31.752}} & \multicolumn{2}{|c|}{24.959} & \multicolumn{2}{|c|}{2.354} & 2.883 & 14.403 & \multicolumn{2}{|c|}{6.017} & \multicolumn{2}{|c|}{ - } & 129.297 & & \\
\hline 1929 & 46.953 & & & \multirow{2}{*}{\multicolumn{2}{|c|}{$\begin{array}{l}25.873 \\
26.282\end{array}$}} & \multicolumn{2}{|c|}{2.397} & 3.021 & 14.388 & \multicolumn{2}{|c|}{6.180} & \multicolumn{2}{|c|}{ - } & 131.687 & & \\
\hline 1930 & 47.318 & \multicolumn{2}{|c|}{33.889} & & & & 418 & 3.100 & 14.276 & 6.36 & & & - & 133.651 & & \\
\hline 1931 & 48.389 & 34.7 & 761 & 26.9 & 49 & & 178 & 3.193 & 14.106 & 6.64 & & & - & 136.218 & & \\
\hline 1932 & 49.674 & 35.6 & 550 & 27.2 & 202 & & 755 & 3.213 & 14.559 & 6.84 & & - & - & 138.694 & & \\
\hline 1933 & 50.294 & 37.6 & 507 & 27.3 & 332 & & 698 & 3.301 & 14.612 & 6.86 & & & - & 141.508 & & \\
\hline 1934 & 51.554 & 39.0 & 41 & 27.1 & 24 & & 746 & 3.288 & 14.595 & 7.03 & & & - & 144.585 & & \\
\hline 1935 & 52.103 & 40.8 & 315 & 26.5 & 588 & & 985 & 3.386 & 14.792 & 7.17 & & & - & 146.843 & & \\
\hline 1936 & 52.705 & 42.1 & & 26.3 & 351 & & 086 & 3.387 & 15.011 & 7.26 & & & - & 148.971 & & \\
\hline 1937 & 52.368 & 42.1 & & 25.8 & 324 & 3.4 & 423 & 4.002 & 14.834 & 8.30 & & & - & $|150.896|$ & & \\
\hline
\end{tabular}

(1) Na 1926 gevormd uit de beide daaronder vermelde deelen.

(2) In 1926 opgeheven en gevoegd bij District Suriname. 
VERDEELING VAN DE BEVOLKING NAAR DEN LANDAARD (ZONDER BOSCHNEGERS EN INDIANEN)

\begin{tabular}{|c|c|c|c|c|c|c|c|c|c|c|c|c|c|c|}
\hline \multirow{2}{*}{$\begin{array}{r}\text { Jaren } \\
\text { (op } 31 \\
\text { Dec.) }\end{array}$} & \multicolumn{2}{|c|}{$\begin{array}{c}\text { Europeanen } \\
\text { uit Nederland }\end{array}$} & \multicolumn{2}{|c|}{$\begin{array}{c}\text { Europeanen } \\
\text { van elders }\end{array}$} & \multicolumn{2}{|c|}{ Surinamers } & \multicolumn{2}{|c|}{$\begin{array}{l}\text { Britsch- } \\
\text { Indiers }\end{array}$} & \multicolumn{2}{|c|}{$\begin{array}{l}\text { Nederl.- } \\
\text { Indiers }\end{array}$} & \multicolumn{2}{|c|}{ Chineezen } & \multicolumn{2}{|c|}{ Anderen } \\
\hline & m. & vr. & $\mathrm{m}$. & vr. & $\mathrm{m}$. & vr. & $\mathrm{m}$. & vr. & $\mathrm{m}$. & vr. & $\mathrm{m}$. & vr. & $\mathrm{m}$. & vr. \\
\hline 1920 & 447 & 328 & 247 & 37 & 24.456 & 27.969 & 15.600 & 10.496 & 7.167 & 4.313 & 693 & & 1.719 & 1.317 \\
\hline 1921 & - & - & - & - & - & - & - & - & - & - & - & - & - & - \\
\hline 1922 & - & - & - & - & - & - & - & - & - & - & - & - & - & -7 \\
\hline 1923 & 482 & 235 & 436 & 243 & 26.000 & 29.138 & 17.104 & 13.426 & 10.776 & 7.753 & 1.009 & 304 & 2.234 & 1.793 \\
\hline 1924 & 461 & 251 & 453 & 253 & 26.699 & 29.5 & 17.451 & 13.5 & 10.998 & 7.687 & 1.12 & 32 & 2.196 & 1.757 \\
\hline 1925 & 426 & 270 & 529 & 243 & 27.40 & 30.948 & 18.066 & 14.467 & 12.776 & 9.425 & 1.276 & 30 & 2.1 & 1.688 \\
\hline 1926 & 431 & 282 & 556 & 249 & 26.76 & 30.831 & 18.324 & 14.858 & 14.568 & 10.923 & 1.278 & 292 & 2.020 & 1.607 \\
\hline 192 & 443 & & 525 & 260 & 27.1 & 31.3 & 18.530 & 15. & 15.569 & 11.821 & 1.256 & 259 & 1.919 & 1.526 \\
\hline 192 & 570 & & 50 & & & & 18.8 & 15. & 16.785 & 12.6 & 1.3 & & 1.9 & \\
\hline 192 & 581 & 329 & 508 & 25 & 27.2 & & 19.204 & 16. & 17.200 & 13.136 & 1.3 & 37 & 2.0 & 1.536 \\
\hline 1930 & 592 & 337 & 514 & 264 & 27.5 & 32.168 & 19.456 & 16.4 & 17.462 & 13.463 & $1.4 \mathrm{C}$ & 39 & 2.06 & 1.562 \\
\hline 193 & & & & 26 & 28.0 & .725 & 19.899 & 16.855 & 17.972 & 13.801 & 1.4 & 3 & 2.0 & 1.593 \\
\hline 1932 & 581 & & & 29 & 28.438 & 33.2 & 20.285 & 17.1 & 18.032 & 14.225 & 1.470 & 43 & 2.06 & 1.590 \\
\hline 1933 & 593 & 334 & 620 & 311 & 28.924 & 33.7 & 20.738 & 17.5 & 18.272 & 14.650 & 1.547 & 46 & 2.110 & 1.597 \\
\hline 1934 & 597 & 342 & 621 & 326 & 29.609 & 34.3 & 21.278 & 18.115 & 18.604 & 14.956 & 1.541 & 47 & 1.996 & 1.554 \\
\hline 1935 & 611 & 342 & 646 & 339 & 30.228 & 34.958 & 21.847 & 18.930 & 18.436 & 14.950 & 1.598 & 478 & 1.990 & 1.490 \\
\hline 1936 & 626 & 351 & 649 & 336 & 30.699 & 35.480 & 22.087 & 19.266 & 18.535 & 15.241 & 1.654 & 490 & 2.048 & 1.509 \\
\hline 1937 & 624 & 304 & 654 & 341 & 31.685 & 36.064 & 23.119 & 20.725 & 17.417 & 14.513 & 1.644 & 515 & 1.866 & 1.348 \\
\hline
\end{tabular}


VERDEELING VAN DE BEVOLKING NAAR DE KERKGENOOTSCHAPPEN (ZONDER BOSCHNEGERS EN INDIANEN)

\begin{tabular}{|c|c|c|c|c|c|c|c|c|c|c|c|c|c|c|c|c|c|c|}
\hline Gezindte & 1920 & 1921 & 1922 & 1923 & 1924 & 1925 & 1926 & 1927 & 1928 & 1929 & 1930 & 1931 & 1932 & 1933 & 1934 & 1935 & 1936 & I937 \\
\hline Nederl. Hervormd & & & 6.867 & 6.909 & 7.172 & 7.208 & 7.271 & \begin{tabular}{|l|} 
\\
7.590 \\
\end{tabular} & 7.782 & 6.973 & 7.083 & 7.263 & 7.597 & 7.889 & 8.014 & 8.120 & 8.400 & 8.550 \\
\hline Evang. Luthersch . & & & 2.864 & 2.748 & 2.768 & 2.749 & 2.861 & 3.149 & 3.203 & 2.442 & 2.507 & 2.607 & 2.900 & 2.920 & 3.011 & 3.040 & 3.700 & 3.800 \\
\hline Roomsch Katholiek & & & 23.418 & 28.987 & 24.116 & 24.565 & 24.062 & 24.585 & 25.219 & 25.655 & 25.812 & 26.326 & 26.752 & 27.294 & 27.582 & $|28.450|$ & 29.535 & 29.124 \\
\hline Evang. Broedergemeente & & & 27.162 & 23.987 & 29.162 & 30.132 & 29.170 & 29.719 & 30.024 & 29.655 & 30.286 & 30.799 & 29.124 & 29.453 & 30.037 & 30.754 & 26.882 & 29.727 \\
\hline Israēl. gemeente . . . . & & & 786 & 818 & 738 & 699 & 750 & 766 & 756 & 618 & 628 & 640 & 762 & 769 & 782 & 780 & 780 & 780 \\
\hline Vrije Evangelisatie . . . & & & 205 & 213 & 184 & 191 & 180 & 169 & 134 & 186 & 188 & 199 & 76 & 79 & 81 & 67 & 65 & 66 \\
\hline Episcopaalsche gemeente & & & 997 & 1.021 & 1.235 & 1.158 & 1.121 & 1.110 & 1.261 & 1.272 & 1.306 & 1.327 & 1.493 & 1.567 & 1.593 & 313 & 335 & 357 \\
\hline Doopsgezinden . . . . & & & 119 & 108 & 118 & 106 & 123 & 115 & 119 & 60 & 66 & 73 & 559 & 529 & 503 & 527 & 527 & 527 \\
\hline Mohammedanen . . . . & & & 24.364 & 25.544 & 28.549 & 25.523 & 34.536 & 34.235 & 35.592 & 35.675 & 36.005 & 36.649 & 36.098 & 36.899 & 39.972 & 40.860 & 42.000 & 41.300 \\
\hline Hindoes . . . . . . . & & & 22.450 & 22.667 & 25.765 & 26.283 & 20.719 & 23.384 & 23.689 & 27.605 & 27.805 & 28.301 & 30.111 & $|30.667|$ & 29.841 & $|30.360|$ & 32.000 & 32.000 \\
\hline Volgelingen v. Confucius & & & 424 & 507 & 607 & 611 & 711 & 710 & 1.100 & 1.061 & 1.140 & 1.182 & 1.280 & 1.214 & 1.289 & 1.220 & 1.300 & 1.300 \\
\hline Dverigen . . . . . . . & & & 1.277 & 1.231 & 644 & 701 & 478 & 509 & 418 & 770 & 825 & 852 & 1.942 & $\mid 2.228$ & 1.680 & $|2.352|$ & 3.447 & 3.365 \\
\hline
\end{tabular}

